\title{
Monitoring and Control of a Laboratory Scale Wind Farm
}

\author{
J.M. Roldán Fernández ${ }^{1}$, M.A. Caballero Gutierrez ${ }^{1}$, J.C. del Pino López ${ }^{1}$, \\ A.G. González Rodríguez ${ }^{2}$ and M. Burgos Payán ${ }^{1}$ \\ ${ }^{1}$ Department of Electrical Engineering, University of Seville \\ Camino de los Descubrimientos, s/n- 41092 Sevilla, Spain \\ phone: +34 954487283 - fax: +34954 487284 - e-mail: vaisat@us.es, mburgos@us.es \\ ${ }^{2}$ Department of Electronic, University of Jaén \\ Escuela Politécnica Superior - Campus "Las Lagunillas" - 23071 Jaén, Spain \\ phone: +34 953212424 - fax: +34 953212400 - e-mail: agaspar@ujaen.es
}

\begin{abstract}
A small laboratory work bench facility for the experimental analysis of wind farms is described. The project was based on the design and assembly, in the Electrical Engineering Laboratory, of a small grid on the laboratory scale (low voltage and power), to experimentally analyze the impact of the integration of a wind farm (in fact only one induction generator) in the electrical energy transport and distribution grid. A virtual instrument specifically developed for this work, allows both the monitoring and control of the scaled wind farm installation. This integrated platform of supervision and control is the user interface, so it has been developed as friendly and self-explanatory as possible. This way, the users have not to expend extra time to learn it.
\end{abstract}

\section{Key words}

Wind energy, Induction generators, Electromagnetic transients, Virtual instrumentation.

\section{Introduction}

The installation of wind farms to convert the kinetic energy of the wind into electrical energy is stimulated by very well-known economic and social factors. The use of renewable energy as a power resource, as in the wind energy case, shows doubtless advantages, however, there are still also some technical difficulties that represent a challenge for the Electrical Engineering [1-2].

One of the problems related to the installation of a wind farm is the potential risk of power quality degradation at the point of common coupling that can be related, basically, to three main factors [3-8].

- The structure of the electrical energy transport and distribution grids, mainly designed, protected and operated to feed passive loads.

- The random nature of the primary power resource, the wind, that makes difficult the forecast of the generation and that causes that these types of facilities operate almost in a continuous transient state.
- The characteristics of the induction generators, commonly used in this type of facilities due to its high technical-economic benefits, that can inject active power (generator) in the transport and distribution grid but always consume reactive energy (load), or their inefficiency to control the generated voltage and frequency.

The objective of the project was the design and assembly of a platform that allows for the theoretical-experimental analysis of the impact of the integration of a wind farm in the electrical energy transport and distribution grid, with both educational and research (introduction) purpose [910]. Since it would not be realistic pretend to have access to a real wind farm, a small grid on the laboratory scale (low voltage and low power) that simulates a wind farm has been designed and installed. The platform includes the main components of a typical wind farm, such as the wind turbine, the induction generator, the soft-starting device, the high voltage transformer, the reactive compensation capacitor bank, a local load in the neighbourhood of the wind farm, the overhead line of evacuation of energy, the energy evacuation substation and the high voltage line. A DC motor, driving the shaft of the induction machine, allows to physically simulating the mechanical torque of the wind turbine. Figure 1 shows a typical diagram of the connection of a wind farm installation to the electric energy transport and distribution grid and the laboratory scale wind farm.

In order to be able to perform an experimental study of the operation of the scaled wind farm installation, a system for monitoring, control and visualization of the main mechanical and electrical magnitudes in a few points of the grid in real time (or almost real time), and for anyone of the different operating conditions (steady state or transient) is needed. So, a virtual instrument has been designed and tested to help the users with the monitoring and control of the system tasks. The developed virtual instrument is based in Labview 5.0 [11] and allows graphically treating and displaying alphanumerically the captured information (characteristics curves, wave spectral analysis, 
calculation of the power or the harmonic content of the waves, etc.). This integrated platform for supervision and control is the interface with the user, so it has been designed as self-explanatory and friendly as possible. This way, the users do not have to dedicate extra time for their learning. The platform has been design with a modular structure that facilitates a possible functionality extension.

\section{Laboratory Scale Wind Farm}

In a typical wind farm, the induction machines usually generate in B.T. $(380$ or $690 \mathrm{~V})$. This voltage usually is transformed to $20 \mathrm{kV}$ the own wind turbine nacelle (present time tend) or on the wind turbine tower base (or in a transformation center that serves to several generators). The generated electrical energy is transported next through an overhead or underground line (more common at present time) to the wind farm substation transformer, which raises the voltage up to 66 $\mathrm{kV}$ (typical) and connects the wind farm with the distribution network. Figure 1 shows the electric distribution system that allows the evacuation of the power generated in the wind farm to the power system.

The models to represent each one of the main components of the wind farm in the scaled installation are the following:

- Induction generator. A three-phase induction machine, squirrel cage rotor, $380 \mathrm{~V} / 660 \mathrm{~V}, 50 \mathrm{~Hz}$, delta connected, $600 \mathrm{~W}$ and $1450 \mathrm{rev}$. $/ \mathrm{min}$. (four poles) has been used.

- Wind turbine. A DC machine, $200 \mathrm{~V}, 500 \mathrm{~W}$ and $1500 \mathrm{rev} . / \mathrm{min}$. is used to "simulate" the mechanical torque produced by the wind turbine.

- Soft-starter. A commercial device with two SCRs connected in opposition per phase (natural commutation) has been used.

- Transformer. The transformers have been modelled by means of its respective short circuit impedances $\left(\mathbf{Z}_{c c}=R_{c c}+\mathbf{j} X_{c c}\right)$.

- Line of energy evacuation. It has been modelled by means of a series impedance $\left(Z_{L}=R_{L}+j X_{L}\right)$ calculated from the typical values of impedance by unit of length of overhead lines.

- The power system. A weak grid has been modelled by means of a transformer.

Table I shows the typical values of impedance of a wind farm installation as the shown in Fig. 1. Table II shows the values of the used impedances to model the installation of the fig. 1 in the installation on scale, in low voltage, mounted in the Laboratory.

The platform installed in the Laboratory integrates the necessary equipment for the measurement and data acquisition such as ammeters, voltmeters, wattmeters, Hall effect current transducers, voltage divider, a data acquisition card and a PC. In addition, the corresponding equipment of protection, control and monitoring is also included.

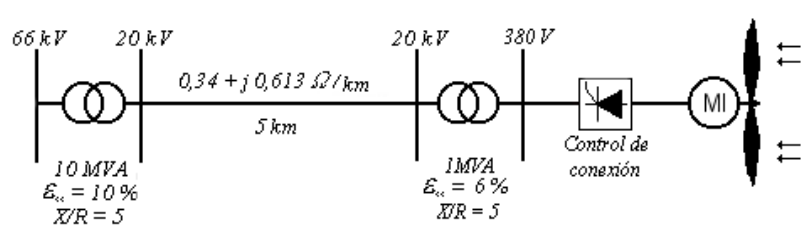

Fig. 1. Typical diagram of the connection of a wind farm to the electric energy transport and distribution network.

TABLE I. Values of impedance for a typical wind farm.

\begin{tabular}{|l|c|c|c|c|c|c|}
\hline \multirow{2}{*}{ Values } & \multicolumn{6}{|c|}{ Impedance $(\boldsymbol{Z}=R+\boldsymbol{j} \cdot X)$} \\
\cline { 2 - 7 } & $\begin{array}{c}R \\
(\Omega)\end{array}$ & $\begin{array}{c}X \\
(\Omega)\end{array}$ & $\begin{array}{c}R \\
(\mathrm{~m} \Omega)\end{array}$ & $\begin{array}{c}X \\
(\mathrm{~m} \Omega)\end{array}$ & $\begin{array}{c}R \\
(\mathrm{~m} \Omega)\end{array}$ & $\begin{array}{c}X \\
(\mathrm{~m} \Omega)\end{array}$ \\
\hline Power System & - & - & - & - & - & - \\
\hline $\begin{array}{l}\text { Transformer } \\
10 \text { MVA }\end{array}$ & 8.54 & 45.71 & 1.95 & 9.80 & 18.84 & 94.40 \\
\hline $\begin{array}{l}\text { Overhead } \\
\text { Line }(5 \mathrm{~km})\end{array}$ & 0.67 & 3.07 & 1.67 & 7.66 & 16.12 & 73.76 \\
\hline $\begin{array}{l}\text { Transformer } \\
\text { 1 MVA }\end{array}$ & 4.70 & 23.53 & 1.17 & 5.88 & 113.28 & 566.39 \\
\hline
\end{tabular}

TABLE II. Values of impedance. Scaled installation (380 V).

\begin{tabular}{|l|c|c|c|}
\hline \multirow{2}{*}{ Values } & \multicolumn{3}{|c|}{ Impedance $(\boldsymbol{Z}=R+\boldsymbol{j} \cdot 2 \pi \mathrm{f} L)$ at $380 \mathrm{~V}$} \\
\cline { 2 - 4 } & $R(\mathrm{~m} \Omega)$ & $L(\mathrm{mH})$ & $X(\mathrm{~m} \Omega)$ \\
\hline Autotransformer & 330 & 77.99 & 490 \\
\hline Transformer 10 MVA & 20 & 0.3 & 1.88 \\
\hline Overhead line (5 km) & 10 & 0.24 & 1.51 \\
\hline Transformer 1 MVA & 100 & 1.81 & 11.37 \\
\hline
\end{tabular}

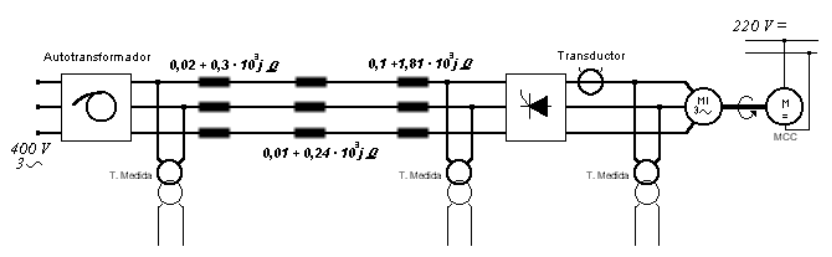

Fig. 2. Basic electric diagram of the laboratory scale wind farm.

Figure 2 shows some of the voltage transformers and Hall effect current transducers, as part of the instrumentation included in the platform. Most part of the control and monitoring systems are integrated in a virtual instrument.

\section{Virtual Instrument}

A virtual instrument is a tool developed by software with the help of the card of data acquisition. The instrument takes the information from field and puts it to disposition of the user through a personal computer. The instrument allows, in addition, a treatment, processing and storage of the obtained signals.

The integrated surroundings of used measurement (virtual instrument) consist, basically, of a PC and a of data acquisition card NI AT-MIO-16L9, with coupling box SCB-68. Also a few transducers and of signal adapters like measurement transformers and voltage dividers have been used, as well as Hall effect current 
transducers for the measurement of currents. The virtual instrument has been developed using Labview 5.0.

The programs based on graphical programming or virtual instruments consist of an interactive user interface, the Frontal Panel and a Data Flow Diagram that makes the functions of source code. For this work several modules or virtual sub-instruments have been developed to carry out the different required tasks. It must notice that each of the modules (or virtual sub-instrument) is, in itself, a virtual instrument, since they have own autonomy as far as its execution refers, although they could need some parameters coming from other modules.

The file of the main interface is called "inicio.vi". When this file is executed, it will display the main screen shown Fig. 3. From this main screen, the user can access to all the tasks programmed in this virtual instrument. The application has a modular structure that facilitates a possible functionality extension and allows an easy modification of the program, as well as the reusability of the different virtual sub-instruments for other possible applications.

The main module "inicio" calls to the other modules so that they execute their different programmed tasks. Each of these modules, once activated, displays its own frontal panel with the task options. The generated structure to obtain this type of interrelation between these two levels of the application modules is based on the execution of all the tasks of the subprograms of the inferior level within a "while" loop (Fig. 4). The while instruction (loop) will not finish until activates the exit variable (button to return or to leave).

As can be seen in Fig. 3, in the upper part of the frontal panel of the main module (Conexión/Desconexión del Generador de Inducción a la red Connection/Disconnection of the Induction Generator to the Grid) there are a group of six buttons related to the control of the start-up and disconnection. Three types of strategies of temporary variation of the applied voltage are offered:

- Linear

$$
\alpha(t)=k_{1} \cdot t+k_{2}
$$

- Linear with a ramp change (two linear sections)

$$
\alpha(t)=k_{1} \cdot t+k_{2} \text { y } \alpha(t)=k_{3} \cdot t+k_{4}
$$

- $\quad$ Squared root

$$
\alpha(t)=k_{1} \cdot \sqrt{ } t+k_{2}
$$

In the left central part, the buttons related to the steady state operation offers four basic options:

- $\quad$ Spectral analysis (Análisis spectral)

- Magnitudes of the system (Magnitudes del sistema)

- Characteristic curves (Curvas caracterísiticas)

- Wind (Viento)

In the right central part, two additional options related to the steady state operation are offered:

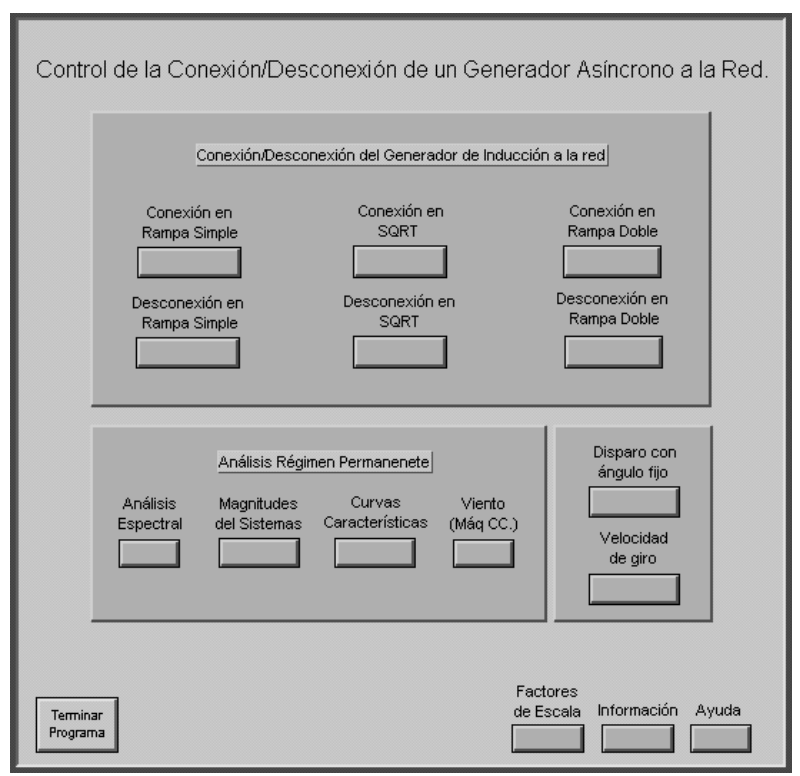

Fig. 3. Frontal panel of the main module of the virtual instrument (inicio.vi).

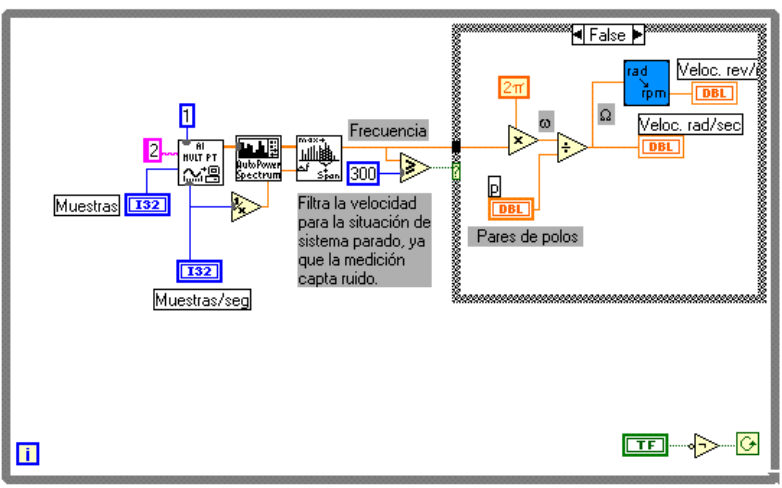

Fig. 4. Structure of subprogram ( "while" loop).

- Operation of the induction machine with constant firing angle

- Operation with constant speed

In the right down part appears three buttons. The first of them (Factores de escala) allows the adjustment of the scale factors of the transducers. The second (Information) offers information about the virtual instrument and third (Ayuda) it is the typical button of help.

\section{Experimental Results}

The platform of test installed in the Laboratory as much allows to the accomplishment and the analysis of tests in steady state as transient that can be grouped according to the following list:

- Steady state

- Characteristic curves (magnitude vs. speed)

- Spectral analysis (voltage and current harmonic content)

- Detection of the critical soft-starter control angle

- Effect of voltage variation

- Transient state 
- Direct switching of the induction generator to the network (from rest to steady state speed)

- $\quad$ Soft starting (from rest to steady state speed)

- Soft disconnection

- Variation of the wind speed and gusts

Figure 5 shows a Power-Speed characteristic obtained in steady state, varying the speed (points) from $1400 \mathrm{rev}$. /min. (motor operation) to $1560 \mathrm{rev}$. /min. (generator operation).

Figure 6 shows an example with the multiple acquisition module. In this example the current wave in a phase and the voltage of line in three different points from the circuit can be seen: at the common coupling (feeding grid), to the entrance of the soft-starter and in the induction generator terminals.

Figures 7 and 8 illustrate the operation of the induction generator with the soft starter working with a firing angle of $\alpha=130^{\circ}$. Figure 7 shows another multiple acquisition with the cutting effect in the voltage waves and current due to the operation of the soft starter. An example of the spectral analysis module can be seen in Fig. 8.

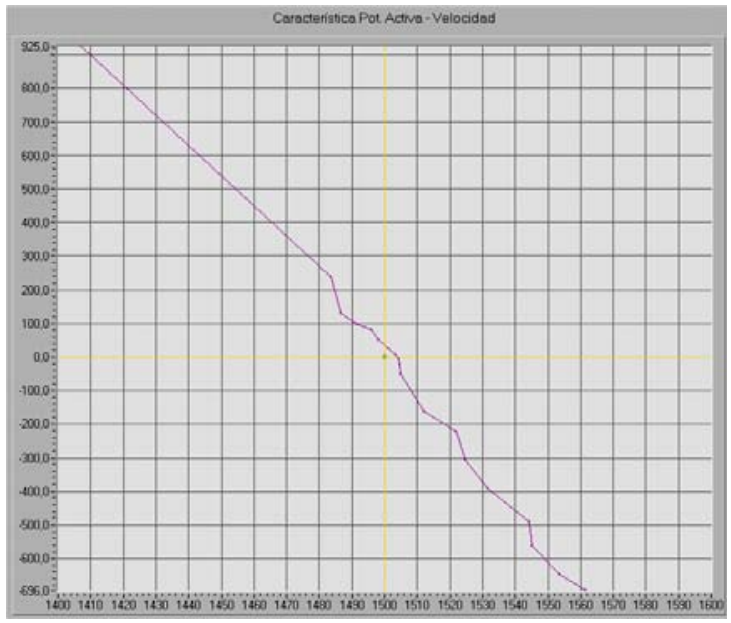

Fig. 5. Active Power (W) - Speed (rev. /min)

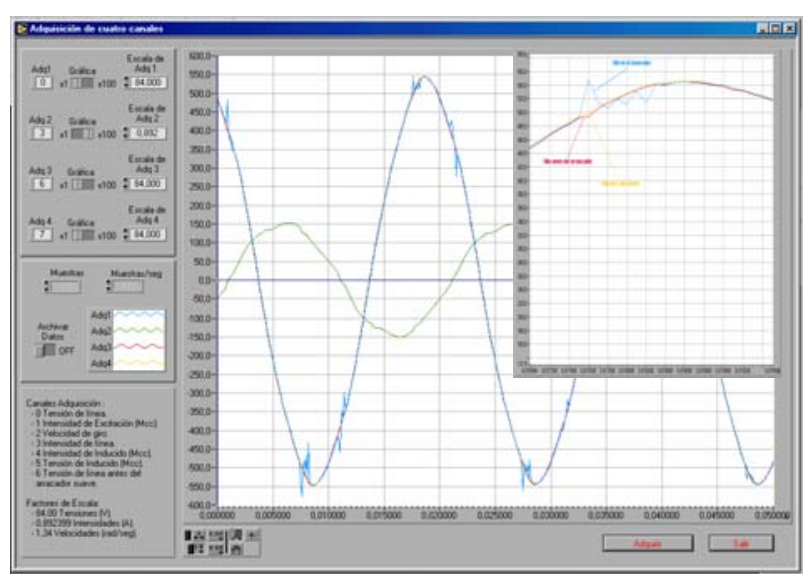

Fig. 6. Multiple acquisition. Current (green), voltage grid AB (yellow), voltage before the soft-starter (red) and induction generator voltage (blue).

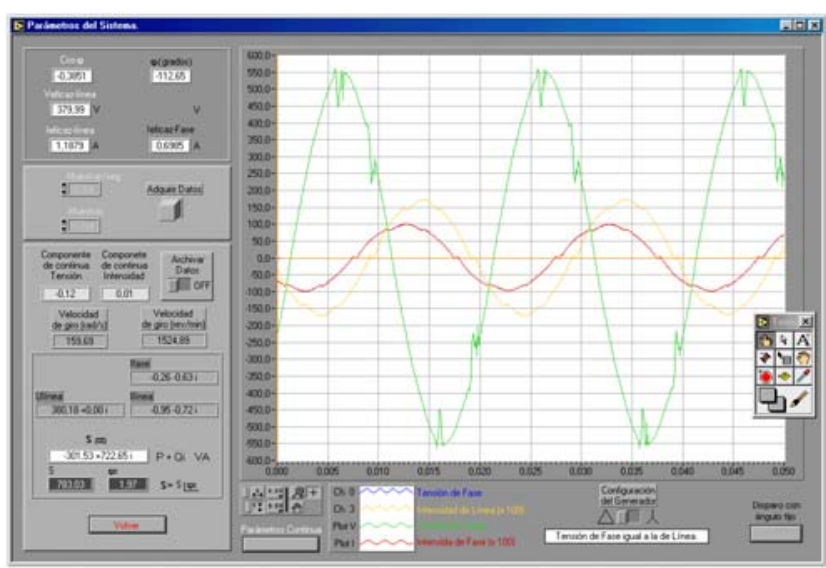

Fig. 7. Steady state operation of the induction generator with $\alpha=130^{\circ}$ (generator).

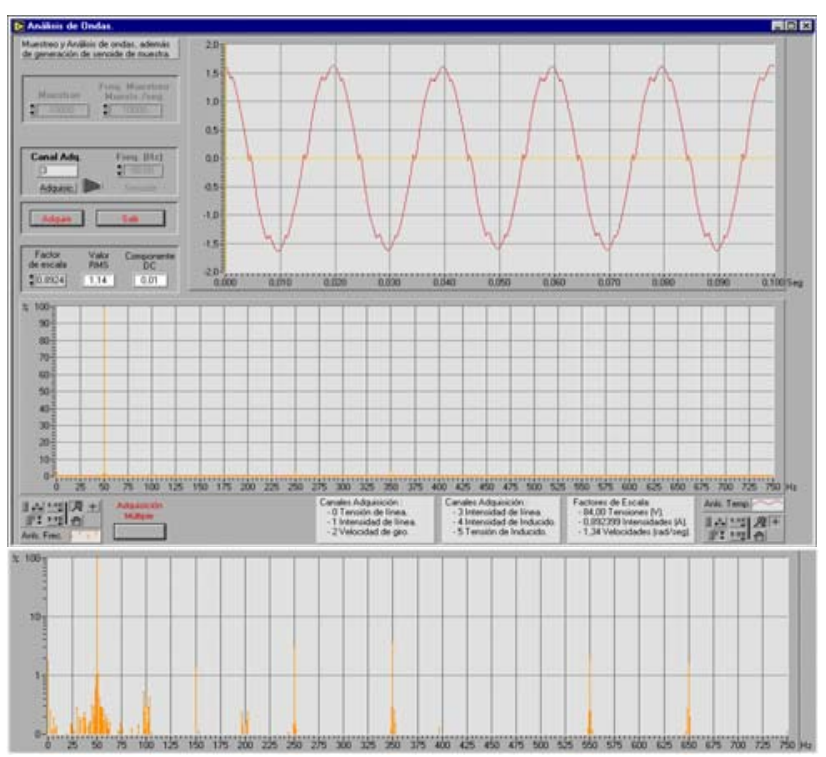

Fig. 8. Induction generator current wave with $\alpha=130^{\circ}$ (generator).

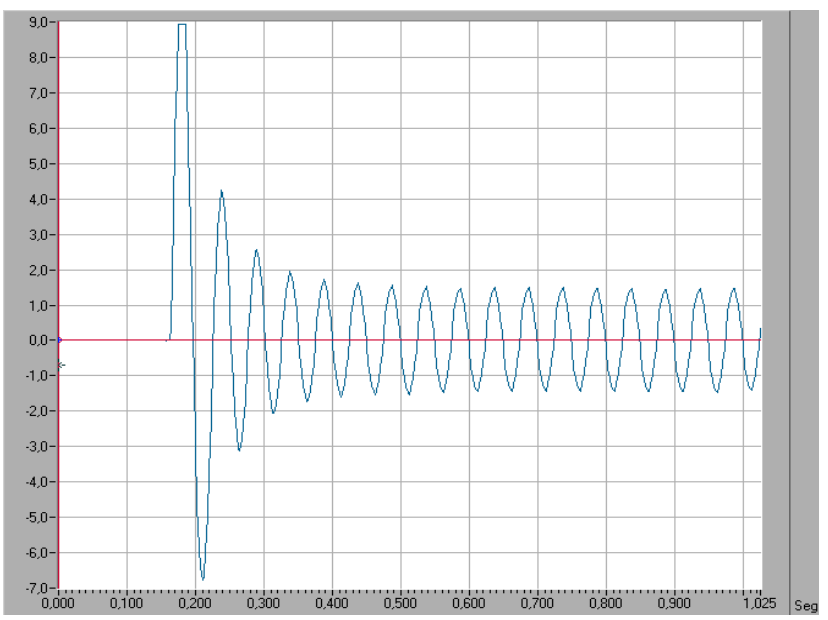

Fig. 9. Current wave for a direct-on-line connection of the induction generator with $\mathrm{N}=1600 \mathrm{rev}$. $/ \mathrm{min}$. 


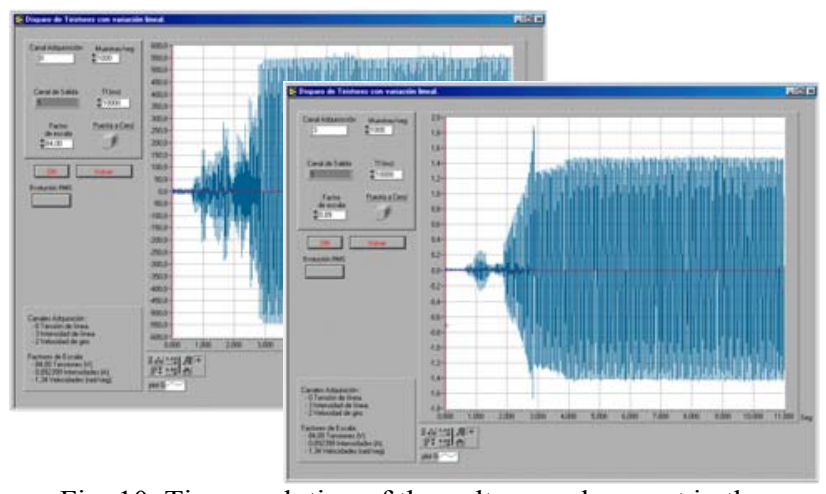

Fig. 10. Time evolution of the voltage and current in the induction generator during a soft starting with root-quadratic evolution of the firing angle.

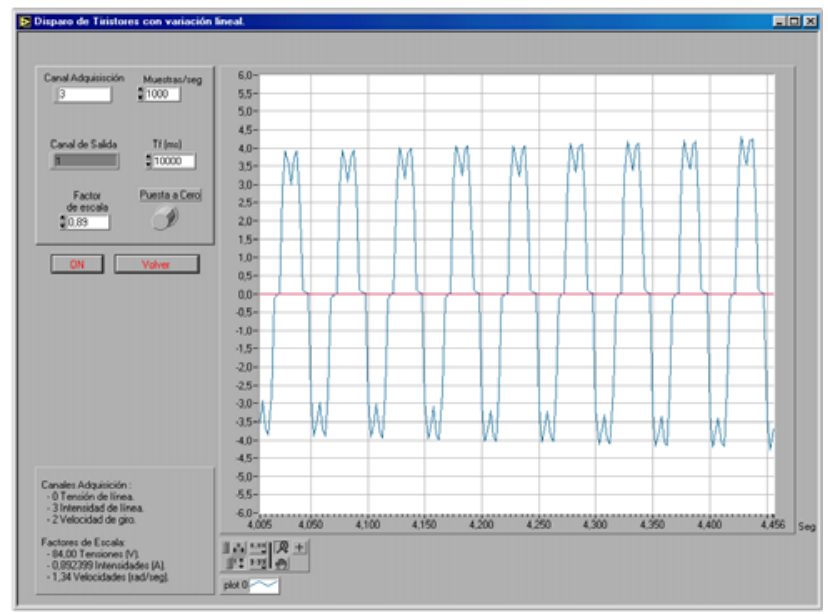

Fig. 11. Detail of the evolution of current in the induction generator during a soft-starting.

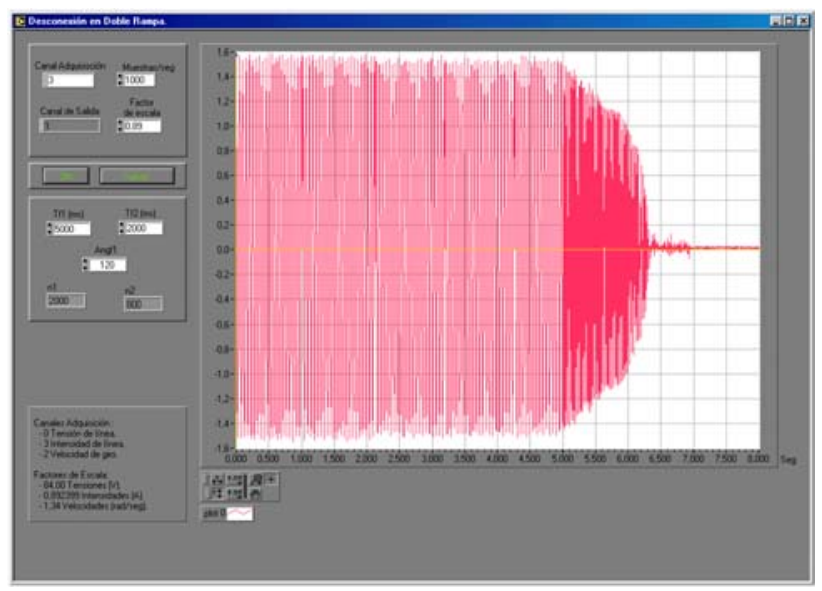

Fig. 12. Time evolution of the induction generator current during a disconnection with double ramp control.

Figure 9 shows the result of a test in transient state. In particular it shows the intensity of direct connection of the induction generator the grid, dividing of an initial speed of $\mathrm{N}=1600 \mathrm{rev}$. $/ \mathrm{min}$. As it can be seen, although part of a speed next to the one of synchronism, a strong end of intensity takes place that is attenuated later, in the steady state.

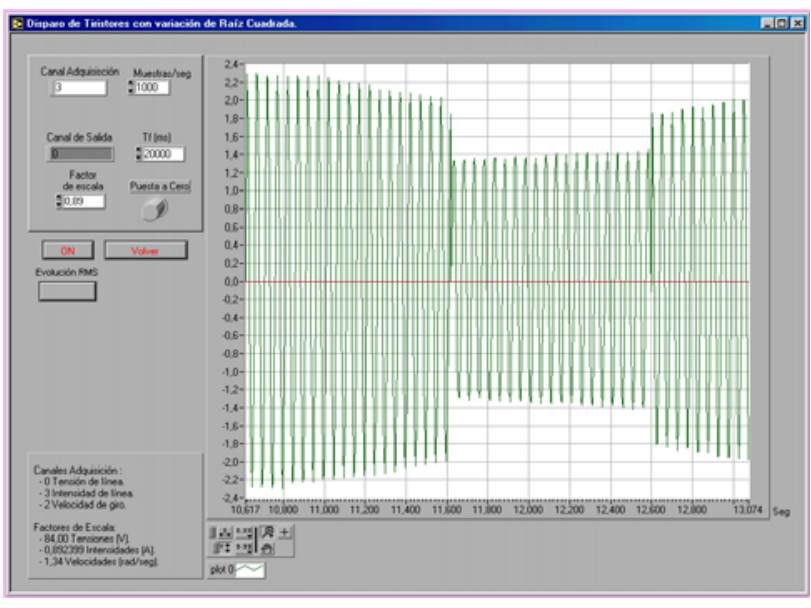

Fig. 13. Time evolution of the in induction generator current during a wind gust.

Figures 10 and 11 show the temporal evolution of the voltage and current in the terminals of the induction generator during a soft start-up with squared root firing angle control. As can bee seen in Fig. 10, although the induction machine starts from the rest, the maximum starting current has been reduced. Figure 11 shows a detail of the deformation in the current wave during the soft starting process.

Finally, Fig. 12 illustrates the temporal evolution of the induction generator current during a disconnection with double ramp control. Figure 13 shows the temporal evolution of the induction generator current during a wind gust. This effect is produced by varying the operation speed with the DC machine.

\section{Conclusion}

A small network on the laboratory scale, low voltage and low power, that simulates a scaled wind farm has been designed and installed. So, a new platform that allows for the theoretical-experimental analysis of the impact of the integration of a wind farm in the electrical energy transport and distribution network is now available at the Electrical Engineering Laboratory of the University of Seville.

To control and monitor the system is a virtual instrument based in Labview 5.0 specifically designed ant tested for this application. This integrated supervision and control platform is the interface with the user, so it has been designed as self-explanatory and friendly as possible. This way, the users do not have to dedicate extra time for learning.

The platform has been design with a modular structure that facilitates a possible extension of its functionality.

The developed infrastructure can be used for a broad kind of experimental studies, work-shops or students' degree thesis related to the wind farms integration. 


\section{Acknowledgement}

The authors would like to acknowledge the financial support provided by ICE of the University of Seville.

\section{References}

[1] M. Burgos Payán, Á.G. González Rodríguez, M.A. Vallejo Saura, Generadores de Inducción en las Prácticas de Laboratorio, REVISTA DE ENSEÑANZA UNIVERSITARIA, No. 7-8, Junio-Diciembre 1994, pp. 87101.

[2] A.M. Gole, O.B. Nayak, T.S. Sidhu, M.S. Sachdev, A Graphical Electromagnetic Simulation Laboratory for Power Systems Engineering Programs, IEEE TRANS. ON POWER SYSTEMS, Vol 11, No. 2, May 1996, pp. 599-606.

[3] A.G. González Rodríguez, M. Burgos Payán, C. Izquierdo Mitchel, PSCAD Based Simulation of the Connection of a Wind Generator to the Network. Proc. 2001 IEEE Porto Power Tech, Vol 4.

[4] A. G. González Rodríguez, M. Burgos Payán, C. Izquierdo Mitchell, Improving Soft-Starting of Induction Generator, in Proc. ICEM 2002, Vol. 4, Bruges.
[5] Á.G. González Rodríguez, M. Burgos Payán, Á.L. Trigo García, J.M. Roldán Fernández and Carlos Izquierdo Mitchell, The Improvement of Induction Generator SoftStart, Actas del $8^{\circ}$ Congreso Hispano-Luso de Ingeniería Eléctrica. Lisboa, 2003.

[6] M. Burgos Payán, M.A. Caballero Gutiérrez, M. Casal GómezCaminero, P.L. Cruz Romero, J.M. Maza Ortega, J.M. Roldán Fernández, A.L. Trigo García, A. de la Villa Jaén, Á.G. González Rodríguez, Generadores de Inducción en un Parque Eólico de Laboratorio, La Innovación en la Enseñanza Superior, ICE Universidad de Sevilla, 2006, pp. 449-466.

[7] Danish Wind Industry Association. http://www.windpower.org

[8] European Wind Energy Association. http://www.ewea.org

[9] J.M. Roldán Fernández, Análisis y Simulación de Transitorios en Parque Eólicos, Proyecto Fin de Carrera, Dpto. Ingeniería Eléctrica de la Universidad de Sevilla, 2003.

[10]M.Á. Caballero Gutiérrez, Estudio Teórico-Experimental de Transitorios en Parque Eólicos, Proyecto Fin de Carrera, Dpto. Ingeniería Eléctrica de la Universidad de Sevilla, 2003.

[11]R.H. Bishop, Labview 6i Manual (Student edition), National Instruments, Prentice Hall, 2000. 